\title{
Türk Milli Boksör ve Kickbokscularda Üst Vücut Kuvvet Özelliği ve Bench Throw Hareketi Esnasındaki Bazı Parametrelerin Karşılaştırılması *
}

\author{
Comparison of Some Parameters During Bench Throw Movement and Upper- \\ Body Strength Characteristics in Turkish National Boxers and Kickboxers
}

\author{
ORİJINAL ARAŞTIRMA/ \\ ORIGINAL RESEARCH \\ İbrahim $\mathrm{CAN}^{1 \dagger}$, \\ Serdar BAYRAKDAROĞLU ${ }^{2}$, \\ ${ }^{1}$ Gümüşhane Üniversitesi, Beden \\ Eğitimi ve Spor Yüksekokulu \\ https://orcid.org/0000-0002-2050-1473 \\ ${ }^{2}$ Gümüşhane Üniversitesi, Beden \\ Eğitimi ve Spor Yüksekokulu \\ https://orcid.org/0000-0002-2166-6675
}

\section{Yayın Bilgisi}

Gönderi Tarihi:02.04.2019

Kabul Tarihi: 25.05.2019

Online Yayın Tarihi:30.06.2019

\begin{abstract}
$\ddot{O ̈ z}$
Bu çalışmanın amacı; Türk milli boksör ve kickbokscularda üst vücut kuvvet özelliği ve bench throw hareketi esnasındaki bazı parametrelerin karşılaştırılmasıdır. Bu amaç doğrultusunda Avrupa ve Dünya şampiyonalarında dereceye giren 7 boksör (yaş:

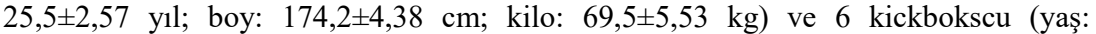
$24,3 \pm 4,03$ y1l; boy: $176,1 \pm 9,45 \mathrm{~cm}$; kilo: $70,5 \pm 10,25 \mathrm{~kg}$ ) olmak üzere toplam 13 sporcu (yaş: $25,0 \pm 3,24$ yıl; boy: $175,1 \pm 6,91 \mathrm{~cm}$; kilo: $70,0 \pm 7,70 \mathrm{~kg}$ ) çalı̧̧maya gönüllü olarak katıldı. Katılımcıların üst vücut kuvvet özelliğini belirlemek için el kavrama ve bench press (BP) hareketinde bir tekrarlı maksimal (1TM) kuvvet testleri uygulandı. Katılımcıların güç ve hız değerlerini belirlemek için isoinertial bir hız dönüştürücü (T-Force dinamik ölçüm sistemi) yoluyla kendi vücut ağırlıklarının \%30'una karşılık gelen bir dış yük kullanılarak bench throw (BT) egzersizi yaptırıldı ve ortalama itme hızı $(\mathrm{OIIH})$, zirve hız $(\mathrm{ZH})$, ortalama itme gücü $(\mathrm{OİG})$ ve zirve güç (ZG) değerleri elde edildi. Verilerin değerlendirilmesinde, shapiro-wilk normallik testi, bağımsız örneklem t-testi, pearson korelasyon analizi ve tanımlayıcı istatistik kullanıldı. Analiz sonuçlarına göre, Türk milli boksör ve kickbokscuların üst vücut kuvvet özelliği ve bench throw hareketi esnasındaki hız ve güç değerleri arasında istatistiksel olarak anlamlı bir farklılık olmadığı elde edildi ( $p>0.05)$. Sonuç olarak, iki grup arasında anlamlı bir farklılık olmamasının hem boksörlerin hem de kickbokscuların Avrupa ve Dünya şampiyonalarına katılan ve dereceye giren üst düzey sporculardan oluşması ve her iki grubun antrenman sistemleri ile çalışma programlarının benzer olmasından kaynaklanabileceği ileri sürülebilir.
\end{abstract}

Anahtar Kelimeler: Boks, Kickboks, Kuvvet, Kinetik, Kinematik

\begin{abstract}
The purpose of this study was to compare some parameters during loaded squat jump movement and upper-body strength characteristics in Turkish national boxers and kickboxers. In accordance with this purpose, 7 boxers (age: 25,5 $\pm 2,57$ years; boy: $174,2 \pm 4,38 \mathrm{~cm}$; weight: $69,5 \pm 5,53 \mathrm{~kg}$ ) and 6 kickboxers (age: $24,3 \pm 4,03$ years; height: $176,1 \pm 9,45 \mathrm{~cm}$; weight: $70,5 \pm 10,25 \mathrm{~kg}$ ) who had ranks in competitions at Europe and

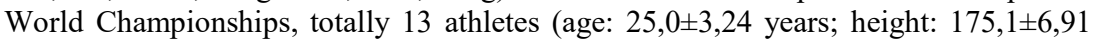
$\mathrm{cm}$; weight: $70,0 \pm 7,70 \mathrm{~kg}$ ), participated voluntarily in this study. In order to obtain upper-body strength characteristic of participants, one repetition maximal (1RM) in bench press (BP) movement and hand-grip strength tests were applied.In order to determine power and velocity parameters, bench throw (BT) movement was applied by using an external load that corresponds to $30 \%$ of body weights of the participants by utilizing an isoinertial velocity transducer (T-Force dynamic measurement system) and values of mean propulsive velocity (MPV), peak velocity (PV), mean propulsive power (MPP) and peak power (PP) were obtained. In the assessment of data, shapirowilk normality test, independent sample t-test, pearson correlation analysis and descriptive statistics were used. According to analysis results, there are no statistically significant differences between velocity and power values during BT movement and upper-body strength characteristics of Turkish national boxers and kickboxers $(\mathrm{p}>0.05)$. As a results, the reason that there are no significant differences bertween both groups; it can be suggested that both groups consist of high-level athletes who participated in Europe and Word championships and their training systems and methods are similar to eachother.
\end{abstract}

Keywords: Box, Kickbox, Strength, Kinetic, Kinematic

\footnotetext{
${ }^{*}$ Bu çalışma, 21-24 Mart 2019 tarihleri arasında Manisa Celal Bayar Üniversitesi, Spor Bilimleri Fakültesi tarafından düzenlenen 2. Dünya Spor Bilimleri Araştırmaları Kongre'sinde sözel sunum olarak sunulmuştur.

† Sorumlu yazar: İbrahim Can, ibrahimcan_61_@hotmail.com
} 


\section{GİRIŞ}

Dövüş sanatları, genel olarak sporcunun beceri ve karakteristik özelliğini geliştirmek, silahsız olarak mücadele etmesini öğretmek gibi gelenekleri içeren bir spor türüdür (Ritschel, 2008). Bu spor türleri arasından boks (Slimani ve ark., 2017a) ve kickboks en modern ve popüler mücadele sporları arasında yer alır (Slimani, Miarka ve Cheour, 2017b). Boks, karşı bir yumruk yemeden rakibe yumruk atmayı amaçlayan tam temaslı bir dövüş sporudur (Guidetti, Musulin ve Baldari, 2002). Bokstan farklı olarak kickboks ise yumruk, tekme, dirsek ve kaval kemiğinin kullanıldığı yine rakibe kuvvetli bir temas uygulamayı hedefleyen bir dövüş sporu türüdür (Buse, 2009).

Dövüş sporlarında genellikle tek bir performans özelliği yeterli değildir. Başarı için çoğu dövüş sporunda kuvvet, güç, hız, teknik, kondisyon gibi özelliklerin bir arada olması gerekir (Franchini, Vecchio, Matsushigue ve Artioli, 2011). Bir boks maçının fiziksel gereksinimlerini karşılayabilmek ve teknik-taktik becerileri uygulayabilmek için iyi gelişmiş bir kas kuvveti ve güce sahip olmak gerekir (Pierce, Reinbold, Lyngard, Goldman ve Pastore, 2006; Piorkowski,

Lees ve Barton, 2011; Chaabene ve ark., 2015). Yumruk atmak boksun temel hareketidir ve etkili bir darbe olması için hem hızlı hem de güçlü atılması gerekir (Pierce ve ark., 2006). Kicboks sporunda, hem üst hem de alt ekstremite kas kuvveti başarının en önemli unsurlarından biridir (Zabukovec ve Tiidus, 1995). Çünkü, etkili bir tekme ve yumruk atmanın önemli olduğu kickboks sporunda başarı için bu temel hareketlerin hem hızlı hem de güçlü şekilde uygulanması gerekir (Slimani, Miarka, Briki ve Cheour, 2016; Slimani ve ark. 2017a).

Literatüre bakıldığında, hem boksörler hem de kickbokscuların fizyolojik ve performans özellikleri üzerine birçok araştırma yapıldığı görülür (Zabukovec ve Tiidus, 1995; Guidetti ve ark., 2002; Chaabene ve ark., 2015, Slimani ve ark., 2016, 2017a, 2017b). Buna karş11k, elit seviyedeki boksörler ve kickbokscuların performans özelliklerinin karşılaştırıldığı herhangi bir çalışma mevcut değildir. Bu bağlamda, Türk milli boksörler ve kickbokscularda üst vücut kuvvet özelliği ve bench throw hareketi esnasındaki bazı parametrelerin (hız ve güç) karşılaştırılması bu araştırmanın amacını oluşturmaktadır. Bu araştırma sonucunda elde edilecek olan sonuçların, her iki spor branşındaki farklılıklar ve üst düzey sportif başarı için gereken performans özelliklerinin belirlenmesine büyük katkılar sağlayacağı ve sonuçların antrenörler, sporcular ve spor bilimleri literatürü için önemli olacağı düşünülmektedir. 


\section{YÖNTEM}

\section{Çalışma Grubu}

Bu çalışmaya, Avrupa ve Dünya şampiyonalarına katılan ve derece yapan 7 boksör (yaş: 25,5 \pm 2,57 y1l; boy: 174,2 \pm 4,38 cm; kilo: 69,5 $\pm 5,53 \mathrm{~kg}$ ) ve 6 kickbokscu (yaş: 24,3 \pm 4,03 y1l; boy: $176,1 \pm 9,45 \mathrm{~cm}$; kilo: 70,5 $\pm 10,25 \mathrm{~kg}$ ) olmak üzere toplam 13 elit seviyedeki mücadele sporcusu (yaş: $25,0 \pm 3,24$ y1l; boy: $175,1 \pm 6,91 \mathrm{~cm}$; kilo: 70,0 $\pm 7,70 \mathrm{~kg}$ ) gönüllü kat1ld1. Araştırma öncesi deneklere çalışmanın amacı, test prosedürleri, araştırmanın potansiyel riskleri ve yararları hakkında detaylı bilgilendirme yapıldı ve çalışmaya gönüllü katıldıklarına dair yazılı bir onam belgesi imzalatıldı.

\section{Veri Toplama Aracı}

Katılımc1lara uygulanan bir tekrarlı maksimal bench press testi (1TM $\mathrm{BP}_{\mathrm{B}}$ ), Earle ve Beachle (2008) tarafından tasarlanan prosedür kullanılarak Smith makine (Esjim IT7001, Eskisehir, Turkey) üstünde yaptırılmıştır. Bu prosedürde, katılımcıların baş, omuz ve kalçaları bench ile; her iki ayağı ise zemin ile temas halinde olacak bir şekilde (beş nokta teması) sırt üstü yatırıldı. Bir yardımcı, katılımcıların ağırlık barını dirseklerini gergin tuttuğu başlangıç pozisyonuna kadar kaldırmasına yardımcı olmuştur. Güvenlik için yardımcı, barı tutan bireyin başına yakın bir pozisyonda durdu ve bara dokunmaksızın katılımcının barı aşağı ve yukarı kaldırışı esnasında ağırlık barını takip etti. Her tekrar bu pozisyonda başlatıldı. Katılımcı, ağırlık barını meme ucu seviyesine kadar göğsüne dokundurmak için indirdi ve sonra dirseklerini tamamen uzatana kadar devamlı hareketle kaldırdı. Hareket esnasında, katılımcıların beş temas noktası kuralına uymaları ve hareketin en alt bölümünde barı gögüslerinden zıplatmamaları istenmiştir (Moir, 2012). Katılımcıların 1TM tarafından tasarlanan prosedüre göre elde edildi. Bu prosedürde uygulanan işlemler ayrıntılı bir şekilde aşağıda açıklanmıştır.

1. Katılımcılara 10 dakikalık bir 1sınma yaptırıldıktan sonra, 5 - 10 tekrar yapabilecekleri bir yük kullanılarak 1sındırıldılar,

2. Bir (1) dakikalık toparlanma süresi verildi,

3. Katılımcıların ilk basamaktaki yüklerine, 7-9 kg arasında yük eklenerek 3-5 tekrar yapabilecekleri bir isınma yükü belirlendi, 
4. İki (2) dakikalık bir toparlanma süresi verildi,

5. Katılımcıların 3. basamaktaki yüklerine, 7-9 kg arasında yük eklenerek 2 -3 tekrar yapabilecekleri maksimal seviye yakınında bir yük belirlendi,

6. Üç (3) dakikalık bir toparlanma süresi verildi,

7. Katılımcıların 5. basamaktaki yüklerine, $7-9 \mathrm{~kg}$ arasında bir yük eklenerek bir tekrarlı maksimal girişim yaptırıld,

8. Üç (3) dakikalık bir toparlanma süresi verildi,

9. Katılımcılar 7. Basamakta verilen yükü kaldırış denemesinde başarılı olduğunda aynı oranlar kullanılarak ağırlık yeniden artırıldı ama bir tekrarlı maksimal denemesinde başarısız olurlarsa 3-5 kg arası yük azaltılıp kaldırış yaptırıldı,

10. Üç (3) dakikalık toparlanma süresi verildi,

11. Denek uygun teknikle bir tekrarlı maksimali yapana kadar yük artırılıp azaltıldı ve katılımcıların bir tekrarlı maksimal kuvvet değerleri maksimal 5 girişimde belirlendi.

Bench throw (BT) hareketinin itme evresindeki hız (ZH: zirve hız; OİH: ortalama itme hızı) ve güç (ZG: zirve güç; OİG: ortalama itme gücü) parametreleri, bir Smith makine (Esjim IT7001 Eskisehir,Turkey) üstünde doğrusal bir hız dönüştürücü (T-Force Dynamic Measurement System; Ergotech Consulting S.L., Murcia, Spain) barın son bölümüne bağlanarak elde edildi. BT egzersizinde doğru ve güvenilir ölçümleri sağlamak için serbest ağırlıklar yerine smith makine kullanılmasın sebebi; bu aletin dikey yönde hareketi sınırlamasıdır (Kobayashi ve ark., 2013). Katılımcılara kendi vücut ağırlıklarının \%30’una karşılık gelen dış yük kullanılarak maksimal hızlarda $3 \mathrm{kez}$ BT hareketini uygulamaları gerektiği belirtildi. BT hareketi esnasında katılımcılara hafifçe göğsüne dokundurana kadar kontrollü bir biçimde barı indirmeleri ve sonra başla komutuyla birlikte mümkün olduğu kadar hızlı ve yükseğe fırlatmaları gerektiği ifade edildi (Loturco, Artioli, Kobal, Gil ve Franchini, 2014). Bütün kaldırışlar esnasında sporcuların performansını artırmak için güçlü sözel cesaretlendirme sağlanmıştır.

\section{Verilerin Analizi}

Bütün değişkenler ortalama ve standart sapma olarak ifade edildi. Verilerin değerlendirilmesinde, shapiro-wilk normallik testi, bağımsız örneklem t-testi, pearson korelasyon analizi ve tanımlayıcı istatistik kullanıldı. 


\section{BULGULAR}

Katılımcıların fiziksel özellikleri tablo 1'de, üst vücut kuvvet özelliği ve bench throw hareketi esnasındaki hız ve güç parametrelerinin karşılaştırılması tablo 2'de, bu parametreler arasındaki ilişki ise tablo 3'de gösterilmiştir. Analiz sonuçlarına bakıldığında, boksörler ve kickbokscuların üst vücut kuvvet özelliği ve bench throw hareketinin konsantrik evresindeki güç ve hız değerlerinin istatistiksel yönden anlamlı farklılık göstermediği görülmektedir ( $\mathrm{p}>0,05)$. Ayrıca, katılımcıların absolut 1TM $\mathrm{TP}_{\mathrm{BP}}$ değeri ile bench throw hareketi esnasındaki OİH, ZH ve OİG değerleri arasında istatistiksel yönden anlamlı bir ilişkinin mevcut olduğu tespit edildi.

Tablo 1. Katılımcıların fiziksel özellikleri

\begin{tabular}{lcccccccc}
\hline & \multicolumn{4}{c}{ Boksörler } & \multicolumn{3}{c}{ Kickbokscular } \\
\cline { 2 - 9 } Değişkenler & $\mathrm{n}$ & Minimal & Maksimal & Ortalama $( \pm \mathrm{ss})$ & $\mathrm{n}$ & Minimal & Maksimal & Ortalama $( \pm \mathrm{ss})$ \\
\hline Yaş $($ Y11) & 7 & 22,0 & 29,0 & $25,5( \pm 2,57)$ & 6 & 21,0 & 30,0 & $24,3( \pm 4,03)$ \\
\hline Boy $(\mathrm{cm})$ & 7 & 170,0 & 180,0 & $174,2( \pm 4,38)$ & 6 & 164,0 & 185,0 & $176,1( \pm 9,45)$ \\
\hline Kilo $(\mathrm{kg})$ & 7 & 60,0 & 75,0 & $69,5( \pm 5,53)$ & 6 & 62,0 & 85,0 & $70,5( \pm 10,2)$ \\
\hline
\end{tabular}

Tablo 2. Katılımcıların üst vücut kuvvet özelliği ve bench throw hareketi esnasındaki hız ve güç parametrelerinin karşılaştırılması

\begin{tabular}{|c|c|c|c|c|c|c|c|c|}
\hline Değiş̧kenler & Branşlar & $\mathrm{n}$ & Minimal & Maksimal & Ortalama $( \pm s s)$ & df & $\mathbf{t}$ & $\mathbf{P}$ \\
\hline \multirow{2}{*}{ Absolut $1 \mathrm{TM}_{\mathrm{BP}}(\mathrm{kg})$} & Boks & 7 & 85,0 & 115,0 & $100,0( \pm 12,9)$ & \multirow{2}{*}{11} & \multirow{2}{*}{,991 } & \multirow{2}{*}{,343 } \\
\hline & Kickboks & 6 & 75,0 & 115,0 & $92,5( \pm 14,4)$ & & & \\
\hline \multirow{2}{*}{ Relatif $1 \mathrm{TM}_{\mathrm{BP}}(\mathrm{kg})$} & Boks & 7 & 1,16 & 1,66 & $1,44( \pm, 19)$ & \multirow[t]{2}{*}{11} & \multirow{2}{*}{1,313} & \multirow{2}{*}{,216 } \\
\hline & Kickboks & 6 & 1,11 & 1,50 & $1,31( \pm, 14)$ & & & \\
\hline \multirow{2}{*}{$\mathrm{OİH}_{\mathrm{BT}}(\mathrm{m} / \mathrm{sn})$} & Boks & 7 & 1,20 & 1,60 & $1,41( \pm, 16)$ & \multirow{2}{*}{11} & \multirow{2}{*}{1,280} & \multirow{2}{*}{,227 } \\
\hline & Kickboks & 6 & 1,14 & 1,63 & $1,28( \pm, 19)$ & & & \\
\hline \multirow{2}{*}{$\mathrm{ZH}_{\mathrm{BT}}(\mathrm{m} / \mathrm{sn})$} & Boks & 7 & 2,04 & 2,38 & $2,26( \pm, 12)$ & \multirow{2}{*}{11} & \multirow{2}{*}{1,554} & \multirow{2}{*}{, 149} \\
\hline & Kickboks & 6 & 1,98 & 2,41 & $2,14( \pm, 14)$ & & & \\
\hline \multirow{2}{*}{$\mathrm{OİG}_{\mathrm{BT}}(\mathrm{W})$} & Boks & 7 & 246,7 & 367,8 & $295,8( \pm 40,8)$ & \multirow{2}{*}{11} & \multirow{2}{*}{,401 } & \multirow{2}{*}{,696 } \\
\hline & Kickboks & 6 & 213,1 & 413,1 & $282,8( \pm 73,3)$ & & & \\
\hline \multirow{2}{*}{$\mathrm{ZG}_{\mathrm{BT}}(\mathrm{W})$} & Boks & 7 & 532,1 & 724,2 & $634,8( \pm 64,6)$ & \multirow{2}{*}{11} & \multirow{2}{*}{, 138} & \multirow{2}{*}{893} \\
\hline & Kickboks & 6 & 475,1 & 825,1 & $626,8( \pm 138,4)$ & & & \\
\hline
\end{tabular}

p>0,05; ОїН ortalama itme gücü; $\mathrm{ZG}_{\mathrm{BT}}$ : Bench throw hareketindeki zirve güç; $1 \mathrm{TM}_{\mathrm{BP}}$ : bench pres hareketindeki bir tekrarlı maksimal 
Tablo 3. Üst vücut kuvvet özelliği ve bench throw hareketi esnasındaki hız ve güç parametreleri arasındaki ilişki

\begin{tabular}{|c|c|c|c|c|c|}
\hline & & $\mathrm{OİH}_{\mathrm{BT}}$ & $\mathrm{ZH}_{\mathrm{BT}}$ & $\mathrm{OİG}_{\mathrm{BT}}$ & $\mathrm{ZG}_{\mathrm{BT}}$ \\
\hline \multirow{3}{*}{ Absolut $1 \mathrm{TM}_{\mathrm{BP}}$} & Pearson Correlation & $613^{*}$ &, $641^{*}$ &, $611^{*}$ &, 509 \\
\hline & Sig. (2-tailed) &, 026 &, 018 &, 027 &, 076 \\
\hline & $\mathrm{N}$ & 13 & 13 & 13 & 13 \\
\hline \multirow{3}{*}{ Relatif $1 \mathrm{TM}_{\mathrm{BP}}$} & Pearson Correlation & ,397 & ,402 &, 029 &,- 133 \\
\hline & Sig. (2-tailed) &, 179 &, 173 & ,925 & 665 \\
\hline & $\mathrm{N}$ & 13 & 13 & 13 & 13 \\
\hline
\end{tabular}

$\mathrm{P}<0,01$; ОїН ${ }_{\text {Вт: }}$ Bench throw hareketindeki ortalama itme hızı; $\mathrm{ZH}_{\mathrm{BT}}$ : Bench throw hareketindeki zirve hız; OİG ortalama itme gücü; $\mathrm{ZG}_{\mathrm{BT}}$ : Bench throw hareketindeki zirve güç; $1 \mathrm{TM}_{\mathrm{BP}}$ : bench pres hareketindeki bir tekrarlı maksimal

\section{TARTIŞMA VE SONUÇ}

$\mathrm{Bu}$ çalışma, elit seviyede mücadele eden boksörler ve kickbokscuların üst vücut kuvvet özelliği ve bench throw egzersizinin itme evresindeki hız ve güç parametrelerinin karşılaştırıldığı ilk çalışmadır. Bir boks müsabakasında fiziksel gereksinimlerini karşılayabilme ve teknik-taktik becerileri uygulayabilmek için iyi gelişmiş bir kas kuvveti ve gücüne sahip olmak gerekir (Pierce ve ark., 2006; Piorkowski ve ark., 2011; Chaabene ve ark., 2015). Kickboksta ise hem üst hem de alt ekstremite kas kuvveti başarının en önemli unsurlarından biridir (Zabukovec ve Tiidus, 1995). Bu çalışmada, bench press hareketindeki absolut 1TM değerleri boksörler için 100,0 ( \pm $12,9 \mathrm{~kg})$ ve kickbokscular için 92,5 ( $\pm 14,4 \mathrm{~kg}$ ) olarak elde edilirken, relatif 1TM değerleri ise boksörler için 1,44 ( \pm ,19 kg), kickbokscular için 1,31 (, $\pm 14 \mathrm{~kg})$ olarak elde edildi. 1TM değerleri bakımından iki grup arasında hem absolut hem de relatif olarak anlamlı bir farklılık olmadığı elde edildi. Literatüre bakıldığında, Loturco ve ark., (2016) tarafından Brezilya milli takımından elit amatör boksörlerde yapılan çalışmada, katılımcıların bench press hareketindeki bir tekrarlı maksimal izometrik kuvveti 1017.6 ( \pm 26.2 N) olarak elde edildi. Slimani ve ark., (2017b) tarafından amatör ve elit-altı kickbokscularda yapılan çalışmada, deneklerin BP testindeki 1TM kuvvet değerleri amatör kickbokscular için 65.7 ( $\pm 11.2 \mathrm{~kg})$, elit-altı kickbokscular için ise 74.2 ( $\pm 12.4 \mathrm{~kg}$ ) olarak elde edilmiştir. Bizim çalışmamızda elde edilen sonuçların, Slimani ve ark., (2017b) tarafindan yapılan çalışmada elde edilen değerlerden oldukça yüksek olduğu görülür. Bu farklılığın sebebi, sporcuların mücadele seviyesindeki farklılıktan kaynaklandığı ileri sürülebilir.

Bu çalışmada, iki grubun bench throw hareketi esnasındaki hız ve güç değerleri arasında istatistiksel yönden anlamlı bir farklılık bulunmadığı tespit edildi. Boksörler ve kickbokscuların hız ve güç parametrelerine bakıldığında; söylenen sıraya göre ortalama itme hızı için 1,41 ( \pm ,16 


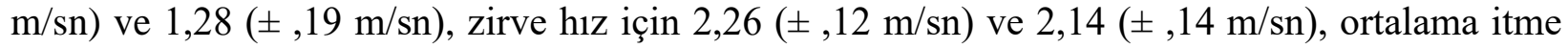
gücü için 295,8 ( \pm 40,8 W) ve 282,8 ( \pm 73,3 W), zirve hız için ise $634,8( \pm 64,6 \mathrm{~W})$ ve $626,8( \pm$ 138,4 W) olarak elde edildi. İki grup arasında anlamlı bir farklılık olmamasının, branşlar ve sporcuların birbirine benzer özelliklerde olmasından kaynaklanabileceği ileri sürülebilir.

Çalışmaya katılan elit amatör sporcuların absolut $1 \mathrm{TM}_{\mathrm{BP}}$ değeri ile bench throw hareketi esnasındaki OİH, ZH ve OİG değerleri arasında istatistiksel olarak anlamlı bir ilişkinin olduğu elde edilirken; relatif 1TM bakımından ise herhangi bir ilişki olmadığı elde edildi. Literatüre bakıldığında, Loturco ve ark., (2016) tarafından Brezilya milli boks takımı oyuncuları üzerinde yapılan bir çalışmada, farklı tekniklerde uygulanan vuruş hızı ile BT egzersizindeki OİG arasında oldukça kuvvetli bir ilişki elde edilmiş ve bu ilişkinin, boksörlerin üst uzuvlarını kullanarak yüksek hızlarda yüksek bir kuvvet uygulayabilmek için yeteneklerini geliştirmelerinin ne kadar önemli olduğunu doğruladığını ileri sürmüşlerdir. Loturco ve ark., (2014) tarafından Brezilya milli karate takımındaki sporcuların üzerinde yapılan başka bir çalışmada, sporcuların hem üst vücut hem de alt vücut için vuruş hızı ile kuvvet ve güç yetenekleri arasında istatistiksel yönden anlamlı bir ilişkinin olduğu tespit edilmiş ve bu ilişkinin vuruş hareketinin dinamik karakterlerinden kaynaklandığı ifade edilmiştir.

Can (2018) tarafından 1. lig hetbolcularda yapılan bir çalışmada ise katılımcıların 1RM $\mathrm{BP}_{\mathrm{B}}$ değerleri ile BT egzersizinin itme evresi esnasında elde edilen OİH ( $\mathrm{r}=, 728), \mathrm{ZH}(\mathrm{r}=, 775)$, OİG $(r=, 703)$ ve ZG $(r=, 759)$ değerleri arasında istatistiksel bakımdan yüksek düzeyde, pozitif ve anlamlı ilişki elde edildi. Bahsi geçen çalışmada, hentbolda pas ve şut atma gibi durumlarda kol firlatma hareketinin çok fazla önem kazanması, üst ekstremite kas gücü ve kuvvetinin firlatma hareketinde büyük bir öneme sahip olmasından dolayı, hentbolcuların BT hareketinin itme evresindeki hız ve güç parametreleri ile $1 \mathrm{RM}_{\mathrm{BP}}$ kuvvet değerleri arasında anlamlı bir ilişkinin olduğu ileri sürülmüştür.

Sonuç olarak, boksörler ve kickbokscuların üst vücut kuvvet özelliği ve BT hareketinin konsantrik evresindeki güç ve hız değerleri arasında anlamlı bir farklılık olmadığı elde edildi. İki grup arasında bir farklılık olmamasının hem boksörler hem de kickbokscuların Avrupa ve Dünya şampiyonalarına katılan ve dereceye giren elit sporculardan oluşması, mücadele bakımından birbirine benzer spor branşları olması ve her iki grubun da antrenman sistemleri ile çalışma programlarının birbirlerine yakın olmasından kaynaklanabileceği ileri sürülebilir. 
Can, İ., ve Bayrakdaroğlu, S. (2019). Türk milli boksör ve kickbokscularda üst vücut kuvvet özelliği ve bench throw hareketi esnasındaki bazı parametrelerin karşılaştırılması. CBÜ Beden Eğitimi ve Spor Bilimleri Dergisi, 14(1), 121-128.

\section{KAYNAKLAR}

Beachle, T.R., Earle, R.W., Wathen, D. (2008). Resistance training. In: Beachle TR, Earle RW. (eds). Essentials of strength training and conditioning. United States: Human Kinetics, 381-412.

Buse, G.J. (2009). Kickboxing. In: Kordi R, Maffulli N, Wroble RR, Wallace WA (eds). In Combat Sports Medicine. New York: Springer.

Can, I. (2018). Analysis on the relation between velocity and power values during propulsive phase of bench throw exercise and upper-body strength characteristics in Professional handball players. European Journal of Physical Education and Sport Science, 4(1), 10-27.

Chaabene, H., Tabben, M., Mkaouer, B., Franchini, E., Negra, Y., Hammami, M., Amara, S., Chaabene, R.B., Hachana, Y. (2015). Amateur boxing: Physical and physiological attributes. Sports Medicine, 45(3), 337-352.

Earle, R.W., Beachle, T.R. (2008). Resistance training and spotting techniques. In: Beachle TR, Earle RW. (eds). Essentials of strength training and conditioning. United States: Human Kinetics, 325-376.

Franchini, E., Vecchio, F.B., Matsushigue, K.A., Artioli, G.G. (2011). Physiological profiles of elite judo athletes. Sport Medicine, 41(2), 147-166.

Guidetti, L., Musulin, A., Baldari, C. (2002). Physiological factors in middleweight boxing performance. The Journal of Sports Medicine and Physical Fitness, 42(3), 309-314.

Kobayashi, Y., Narazaki, K., Akagi, R., Nakagaki, K., Kawamori, N., Ohta, K. (2013). Calculation of force and power during bench throws using a smith machine: The importance of considering the effect of counterweights. International Journal of Sports Medicine, 34(9), 820-824.

Loturco, I., Artioli, G.G., Kobal, R., Gil, S., Franchini, E. (2014). Predicting punching acceleration from selected strength and power variables in elite karate athletes: A multiple regression analysis. Journal of Strength and Conditioning Research, $28(7), 1826-1832$.

Loturco, I., Nakamura, F.Y., Artioli, G.G., Kobal, R., Kitmura, K., Calabad, C.C., Cruz, I.F., Romano, F., Pereira, L.A., Franchini, E. (2016). Strength and power qualities are highly associated with punching impact in elite amateur boxer. Journal of Strength and Conditioning Research, 30(1), 109-116.

Moir, L.G. (2012). Muscular stregth. In: Miller T. (eds). Science of strength and conditioning series: NSCA's guide to tests and assessment. United States: Human Kinetics, 147-191.

Pierce, J.D., Reinbold, K.A., Lyngard, B.C., Goldman, R.J., Pastore, C.M. (2006). Direct measurement of punch force during six professional boxing matches. Journal of Quantitative Analysis in Sports, 2(2), 1-19.

Piorkowski, B.A., Lees, A., Barton, G.J. (2011). Single maximal versus combination punch kinematics. Sports Biomechanics, 10(1), 1-11.

Ritschel, J. (2008). The kickboxing handball. New York: The Rosen Publication Group.

Slimani, M., Miarka, B., Briki, W., Cheour, F. (2016). Comparison of mental toughness and power test performances in highlevel kickboxer by competitive success. Asian Journal of Sports Medicine, 7(2), 1-6.

Slimani, M., Chaabene, H., Davis, P., Franchini, E., Cheour, F., Chamari, K. (2017a). Performance aspects and physiological responses in male amateur boxing competitions: A brief review. Journal of Strength and Conditioning Research, 31(4), $1132-1141$.

Slimani, M., Miarka, B., Cheour, F. (2017b). Effects of competitive level and gender on anthropometric profile and physiological attributes in kickboxers. Collegium Antropolgical, 41(3), 267-274.

Zabukovec, R., Tiidus, P.M. (1995). Physiological and anthropometric profile of elite kickboxers. Journal of Strength and Conditioning Research, 9(4), 240-242. 